\title{
Ongoing COVID-19 Pandemic: A Concise but Updated Comprehensive Review
}

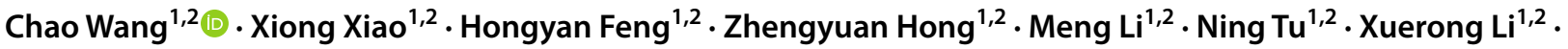 \\ $\mathrm{Ke} \mathrm{Wang}^{1,2} \cdot$ Lihong $\mathrm{Bu}^{1,2}$
}

Received: 10 June 2020 / Accepted: 10 February 2021 / Published online: 13 April 2021

(c) The Author(s), under exclusive licence to Springer Science+Business Media, LLC, part of Springer Nature 2021

\begin{abstract}
An ongoing global outbreak of coronavirus disease 2019 (COVID-19) caused by severe acute respiratory syndrome coronavirus 2 (SARS-CoV-2; previously temporarily named 2019-nCoV) was reported in Wuhan, China at the end of 2019. SARSCoV-2 has become a pandemic and a major public health concern. As of 18 January 2021, the virus has spread all over the world, resulting in over 99,026 cases in China and more than 95 million cases in another 216 countries. After three months of efforts, Chinese authorities have managed to control the outbreak by implementing aggressive and effective measures; by striking contrast, the number of confirmed patients outside China is still rapidly climbing following an exponential growth trend, especially in some European and American countries. To date, no specific therapeutic drugs still exist for COVID19. Therefore, it is of utmost importance to understand the updated comprehensive summary regarding COVID-19, in the hopes of providing a reference for the intervention and prevention of the COVID-19 epidemic for public health authorities and healthcare workers around the world.
\end{abstract}

\begin{tabular}{|c|c|}
\hline \multicolumn{2}{|l|}{ Abbreviations } \\
\hline COVID-19 & Coronavirus disease 2019 \\
\hline WHO & World Health Organization \\
\hline CT & Computed tomography \\
\hline SARS-CoV-2 & $\begin{array}{l}\text { Severe acute respiratory syndrome corona } \\
\text { virus } 2\end{array}$ \\
\hline ARDS & Acute respiratory distress syndrome \\
\hline PHEIC & $\begin{array}{l}\text { Public health emergency of international } \\
\text { concern }\end{array}$ \\
\hline SARS & Severe acute respiratory syndrome \\
\hline GGO & Ground-glass opacity \\
\hline MERS & Middle East respiratory syndrome \\
\hline TCM & Traditional Chinese medicine \\
\hline S-protein & Spike \\
\hline
\end{tabular}

Lihong Bu

bulihongs@whu.edu.cn

1 PET-CT/MR Center, Renmin Hospital of Wuhan University, Wuhan 430060, Hubei, China

2 Molecular Imaging Center, Renmin Hospital of Wuhan University, Wuhan 430060, Hubei, China

\section{Introduction}

Since December 2019, a cluster of cases of "unknown viral pneumonia" linked to a local Huanan seafood wholesale market was reported in Wuhan, China. Scientists isolated a novel coronavirus (named Severe Acute Respiratory Syndrome Coronavirus 2 (SARS-CoV-2)) that was identified as the cause of the unknown pneumonia in an infected patient in Wuhan [1]. Subsequently, the WHO officially named the disease as COVID-19.

Researchers have found that SARS-CoV-2 is closely linked to bat-derived SARS-like coronaviruses [2, 3], indicating probable animal-to-human transmission. Subsequently, more and more studies suggested that SARS-CoV-2 sustained human-to-human transmission [4-6]. A study indicated that hospital-related spread of SARS-CoV-2 was doubted in $41 \%$ of patients [7]. Furthermore, asymptomatic infection was suspected as a potential source of infection [8]. As of 18 January 2021, the ongoing infections have spread throughout China and numerous countries around the world [9-13] and have resulted in 99,026 cases in China and over 95 million cases in 216 other countries. It has overwhelmingly surpassed SARS and MERS in terms of both the number of infected cases and the spatial range of epidemic areas. So far, the accumulative confirmed cases have currently remained almost constant in China, on 18 January 
2021, 232 cases were confirmed, while there still has been a striking rise in COVID-19 in other countries, 173,425 new cases were confirmed in the America and 38,598 in Brazil on 18 January 2021.

Recently, SARS-CoV-2 has become a pandemic, and the number of infected people is growing rapidly around the world. Nevertheless, the epidemic can still be stopped if nations are willing to take aggressive measures, as did China, whose current epidemic is under control. In this paper, we provide the updated comprehensive summary regarding COVID-19, from etiological characteristics to intervention and prevention experience from China, in the hopes of providing a reference for public health authorities and healthcare workers around the world.

\section{Etiological Characteristics}

Coronaviruses, a big family of single-stranded RNA viruses, can transmit animals and humans and can cause aspiratory, hepatic, digestive, and neurological diseases [14]. Coronaviruses are further divided into four genera: alpha-, beta-, gamma-, and delta-coronaviruses [15]. SARS-CoV-2, as SARS-CoV in 2002 and MERS-CoV in 2012, belongs to a separate branch of the $\beta$-coronavirus family [1]. SARS-CoV-2 has been indicated to infect human aspiratory epithelial cells via an interaction between the viral spike (S-protein) and the angiotensin-converting enzyme 2 receptors on human cells, in the same manner as SARS-CoV [16]. A number of studies have shown that SARSCoV2 is most similar to SARS-like coronaviruses from horseshoe bats collected in Zhoushan, Zhejiang, with a nucleotide homology of 87.9-98.7\% [17, 18 ], which is higher than SARS-CoV ( 79\%) and MERS$\mathrm{CoV}(\sim 50 \%)$ [2]; this indicates that bats are the most likely hosts of SARS-CoV-2. Moreover, Xiao et al. [19] found that one coronavirus isolated from a Malayan pangolin showed $100 \%, 98.6 \%, 97.8 \%$ and $90.7 \%$ amino acid identity with SARS-CoV-2 in the E, M, N and S genes, respectively, suggesting that pangolin may be a potential intermediate host. However, Lam et al. [20] expressed a different view, in which multiple lineages of pangolin coronavirus and their analogy to SARS-CoV-2 suggested that pangolins should be considered possible natural hosts. Shi et al. [21] found that SARS-CoV-2 replicates poorly in dogs, pigs, chickens, and ducks, but ferrets and cats were permissive to infection, moreover, cats were susceptible to airborne transmission. Additionally, Richard et al. [22] showed that SARS-CoV-2 was transmitted efficiently via direct contact and via the air between ferrets, 1 to 3 days and 3 to 7 days after exposure, respectively. To date, there is still no clear understanding regarding the natural and intermediate host of SARSCoV2, which warrants further research. What we can learn from SARS is that identifying the source of SARSCoV2 would help determine the transmission pattern of zoonosis and thus containing the ongoing global outbreak.

\section{Epidemiology}

In the beginning stages of the epidemic, a study by Li et al. [5] demonstrated that $55 \%$ of confirmed cases (425 patients) were related to the seafood market, unlike only $8.6 \%$ of the subsequent patients. The average incubation period was 5.1 days (95\% CI 4.1-7.0), and the infection doubled in size every 7.4 days. According to the travel history and symptoms of 88 patients found outside Wuhan, the average incubation period was evaluated to be 6.4 days (95\% CI 5.6-7.7) [23]. Foreign studies have also shown that the average incubation period of SARS-CoV-2 was 3.6 days (95\% CI 1-9) [24]. Subsequently, Guan et al. reported that the median incubation period was 4.0 days (interquartile range: $3-7$ ) in 1099 patients [6]. These estimates will help to provide a reasonable basis for the isolation and release of patients from medical observation. Taken together, China currently defines 14 days as a medical observation period.

At present, the estimated value of the mean basic reproduction rate (R0) of COVID-19 is still disputed. In a previous study, Li et al. [5] evaluated that R0 was 2.2 (95\% CI 1.4-3.9), according to the mean continuous time interval of 7.6 days (95\% CI 5.3-19). As the epidemic progressed, the analysis of the epidemiological data of 8866 patients showed that R0 was 3.77 (95\% CI 3.51-4.05), based on the mean continuous time interval of 7 days [25]. Recently, $\mathrm{Li}$ et al. weighed five independent methods and found that the R0 of COVID-19 was 3.39 (95\% CI 3.09-3.70) during the whole epidemic period, which was higher than that of SARS [26]. This may be one reason why more than 70 million people have been infected in more than 210 countries around the world in the last year with the number of confirmed cases growing rapidly and dramatically [27, 28]. Therefore, in the beginning stages of the epidemic, the value $\mathrm{R} 0=2.2$ (from 425 patients) may have been underestimated, as patients were not diagnosed in time due to a lack of medical resources.

SARS-CoV-2 has become a pandemic, and the number of infections is increasing dramatically. Epidemiological studies have indicated that SARS-CoV-2 is mainly spread by respiratory droplets, and can also be transmitted via direct or indirect contact with mucous membranes in the nose and mouth [29]. Furthermore, KIM et al. [30] found that a few naive indirect contacted confirmed ferrets were positive for viral RNA, suggesting airborne transmission. In addition, a considerable number of cases in the incubation period become a potential source of SARS-CoV-2 infection, as they exhibit atypical symptoms or are even asymptomatic [8]. Recently, besides nasopharyngeal swabs, viral RNA was 
also detected in patients'stool samples [31]. Luo et al. [32] showed that $16 \%$ of confirmed cases presented with gastrointestinal symptoms, suggesting that the digestive tract could be a potential SARS-CoV-2 infection route. Furthermore, positive viral RNA of the newborn at the age of $36 \mathrm{~h}$ suggested that SARS-CoV-2 might cause neonatal infection via mother-to-child transmission, but no reliable evidence is as yet available to support the possibility of vertical transmission of COVID-19 infection [33]. Recent studies have also found that SARS-CoV-2 can be transmitted via the ocular conjunctival route, which provides important theoretical support for virus prevention, especially for the protection of medical workers [34].

\section{Clinical Features and Laboratory Findings}

We summarized the clinical features and laboratory findings of cases with COVID-19 from four different studies (Table 1) [6, 10-12]. Males represented 55.2\% $(\mathrm{n}=899)$

Table 1 Clinical Features and Laboratory Findings from four studies of 1628 patients with SARS-CoV-2 pneumonia in the World [6, 10-12]

\begin{tabular}{|c|c|c|c|c|}
\hline & Guan et al. [6] $(n=1099)$ & Tian et al. [11] $(n=262)$ & Chen et al. [12] $(n=249)$ & Young et al. [10] $(\mathrm{n}=18)$ \\
\hline \multicolumn{5}{|l|}{ Demographics } \\
\hline Data sources & Multiple cities, China & Beijing, China & Shanghai, China & Singapore \\
\hline Age, median (range) y & $47(35-58)$ & $47.5(1-94)$ & $51(36-64)$ & $47(31-73)$ \\
\hline$\geq 65$ years, No $(\%)$ & $153(15.1)$ & $48(18.3)$ & NA & NA \\
\hline Male sex, No (\%) & $637(58.1)$ & $127(48.5)$ & $126(50.6)$ & $9(50)$ \\
\hline Severe cases, No (\%) & $173(15.7)$ & $46(17.6)$ & $22(8.8)$ & $2(11)$ \\
\hline Healthcare worker & $38(3.5)$ & NA & NA & NA \\
\hline \multicolumn{5}{|l|}{ Symptoms, No (\%) } \\
\hline Fever & $975(88.7)$ & $215(82.1)$ & $217(87.1)$ & $13(72)$ \\
\hline Cough & $745(67.8)$ & $120(45.8)$ & $91(36.5)$ & $15(83)$ \\
\hline Shortness of breath & $205(18.7)$ & $18(6.9)$ & $19(7.6)$ & $2(11)$ \\
\hline Fatigue & $419(38.1)$ & $69(26.3)$ & $39(15.7)$ & NA \\
\hline Myalgia & $164(14.9)$ & NA & NA & NA \\
\hline Headache & $150(13.6)$ & $17(6.5)$ & $28(11.2)$ & NA \\
\hline Diarrhea & $42(3.8)$ & NA & $8(3.2)$ & $3(17)$ \\
\hline Rhinorrhea & $53(4.8)$ & NA & $17(6.8)$ & $1(6)$ \\
\hline Sore throat & $153(13.9)$ & NA & $16(6.4)$ & $11(61)$ \\
\hline Asymptomatic & NA & $13(5.0)$ & $7(2.8)$ & 0 \\
\hline Duration of onset to hospitalization & NA & $4.5 \pm 3.7$ & $4(2-7)$ & $>2(50)$ \\
\hline \multicolumn{5}{|l|}{ Coexisting disorder } \\
\hline Any & 261(23.7) & NA & $90(36.1)$ & $5(28)$ \\
\hline $\begin{array}{l}\text { Cardiovascular and cerebrovascular } \\
\text { diseases }\end{array}$ & $42(3.9)$ & NA & $55(21.7)$ & NA \\
\hline Hypertension & $165(15.0)$ & NA & NA & $5(27.8)$ \\
\hline Diabetes & $81(7.4)$ & NA & $25(10.0)$ & $2(11.1)$ \\
\hline Chronic respiratory diseases & $12(1.1)$ & NA & $5(2.0)$ & NA \\
\hline Chronic liver disease & $23(2.1)$ & NA & $2(0.8)$ & NA \\
\hline Malignant tumor & $10(0.9)$ & NA & $1(0.4)$ & 0 \\
\hline \multicolumn{5}{|l|}{ Laboratory findings, median (range) } \\
\hline White blood cells $\left(\times 10^{9} / \mathrm{L}\right)$ & $4.7(3.5-6.0)$ & NA & $4.71(3.80-5.86)$ & $4.6(1.7-6.3)$ \\
\hline Lymphocytes $\left(\times 10^{9} / \mathrm{L}\right)$ & $1(0.7-1.3)$ & NA & $1.12(0.79-1.49)$ & $1.2(0.8-1.7)$ \\
\hline Platelet count $\left(\times 10^{9} / \mathrm{L}\right)$ & $168(132-207)$ & NA & NA & $159(116-217)$ \\
\hline C-reactive protein $(\mathrm{mg} / \mathrm{L})$ & $>10(481 / 793,60.7)$ & NA & $12(4.4-29.4)$ & $16.3(0.9-97.5)$ \\
\hline Alanine aminotransferase (U/L) & $>40(158 / 741,21.3)$ & NA & $23(15-33)$ & NA \\
\hline Aspartate aminotransferase (U/L) & $>40(168 / 757,22.2)$ & NA & $25(20-33)$ & NA \\
\hline Lactate dehydrogenase (U/L) & $>250(277 / 675,41)$ & NA & $229(195-291)$ & $512(285-796)$ \\
\hline
\end{tabular}

Data are $\mathrm{n}(\%), \mathrm{n} / \mathrm{N}(\%)$, mean (standard deviation) or median (interquartile range)

NA not available 
of patients, and 38 healthcare workers had infections in Guan's study [6]. The symptoms of COVID-19 are nonspecific and can range from asymptomatic to acute respiratory distress syndrome. Wang et al. [35] showed that asymptomatic carriers were more frequent amongst middle-aged individuals who had close contact with confirmed patients, which further increased the difficulty of epidemic intervention and prevention. In these four studies, there were a total of 1,628 cases; fever was the most common symptom $(87.2 \%, \mathrm{n}=1420)$, followed by cough $(59.6 \%, \mathrm{n}=971)$, fatigue $(32.7 \%, \mathrm{n}=527)$, and atypical symptoms including diarrhea $(3.8 \%, 3.2 \%)$, rhinorrhea $(4.8 \%, 6.8 \%)$, and sore throat $(13.9 \%, 6.4 \%)$, reported by Guan et al. [6] and Chen et al. [12], respectively. Notably, some digestive symptoms, including diarrhea, nausea, and vomiting, should not be overlooked in patients with COVID-19, and clinicians should be on high alert [32]. Besides, Dell'Era et al. [36] found that some infected people even had taste and smell disorders. Among COVID-19 infections, hypertension and cardiovascular and cerebrovascular diseases were the most common coexisting disorders, followed by diabetes. Patients who were transferred to intensive care units were more possible to have underlying diseases [7] and significantly longer durations of fever compared to those that did not require intensive care units [12]. Furthermore, Liu et al. [37] discovered that pregnant women were more likely to exhibit atypical clinical findings, which increased the difficulty of initial diagnosis. Qiu et al. [38] showed that all 36 children with infections exhibited moderate or mild symptoms, including asymptomatic cases, resulting in a dangerously infectious community situation. A mild respiratory tract infection was frequently the only clinical feature among the first 18 patients diagnosed with SARSCoV-2 infection in Singapore [10]. However, if mild infections are not timely treated, they are likely to develop into severe cases and even death.

Upon admission, Guan et al. showed that leukopenia, lymphocytopenia, and thrombocytopenia occurred in $33.7 \%$, $83.2 \%$, and $36.2 \%$ of cases, respectively, and many infected patients had elevated levels of C-reactive protein [6]. Zhang et al. [39] demonstrated that lymphopenia (75.4\%) and eosinopenia (52.9\%) were discovered in most patients. Liu et al. [40] found that patients with severe symptoms exhibited continuous and obvious decreases in lymphocyte counts and increases in neutrophil counts compared to patients with mild symptoms. Compared to the mild cases, severe cases exhibited significant decreases in $\mathrm{T}$ cell counts as well as increases in IL-2, IL-10, IL-6, and IFN- $\gamma$ levels in peripheral blood. It seems that severe cases have more significant laboratory abnormalities than non-severe cases because of an obvious immunopathological process caused by a cytokine storm. Moreover, further research found that the viral clearance ratio was correlated with decreased serum lactate dehydrogenase and creatine kinase levels; such decreases may thus indicate that the infection is subsiding [41].

\section{Imaging Findings}

Chest computed tomography (CT) plays a vital role in the early diagnosis of COVID-19 [42, 43]. Herein, we summarized the imaging findings of three studies (Table 2) [44-46]. Upon admission of 225 cases, we found that typical CT findings consisted of bilateral pulmonary ground-glass opacity $(84.4 \%, \mathrm{n}=190)$ and pulmonary consolidation $(49.3 \%$, $\mathrm{n}=111)$; lesions were most likely to occur in the right lower lobe $(76.9 \%, \mathrm{n}=173)$ and left lower lobe $(75.6 \%, \mathrm{n}=170)$, and most patients had more than two lobes affected. Moreover, discrete pulmonary nodules, pleural effusion, pulmonary emphysema, pulmonary fibrosis and lymphadenopathy were rare symptoms [45]. Song et al. [47] showed that 44 of $51(86 \%)$ patients had bilateral lung involvement; in $86 \%$ and $80 \%$ of patients, the peripheral and posterior part of the lungs were involved, respectively, patients older than 50 years old were more likely to have lung consolidation than patients younger than 50. Caruso et al. [48] discovered that $93 \%$ of confirmed cases had multilobe and posterior lung involvement; $91 \%$ of cases had bilateral pneumonia.

Pan et al. [42] researched the time course of lung changes on chest CT during recovery from COVID-19, which consisted of the early stage (0-4 days), progressive stage (5-8 days), peak stage (9-13 days), and absorption stage ( $\geq 14$ days). They found that small subpleural ground-glass opacities grew larger and exhibited crazy-paving patterns and consolidation up to two weeks after disease onset. After two weeks, the lesions were slowly absorbed, leaving extensive ground-glass opacity and subpleural parenchymal bands (the absorption stage). Meanwhile, Ai et al. [49] discovered that the accuracy rates of chest CT imaging and RT-PCR assay were $88 \%$ (888/1014) and 59\% (601/1014) for the diagnosis of suspected cases with COVID-19, respectively, indicating that chest $\mathrm{CT}$ had a higher sensitivity for diagnosing COVID-19 than initial RT-PCR. However, Yang et al. [50] expressed a different view, as patients with RT-PCRconfirmed COVID-19 exhibit normal chest CT findings upon admission. This indicates that a normal chest $\mathrm{CT}$ result could not preclude COVID-19, especially for cases in the early stage.

\section{Diagnosis of COVID-19}

Diagnosis of COVID-19 needs a comprehensive analysis of epidemiological history and clinical presentation. Fever and dry cough were the common symptoms of a SARSCoV-2 infection, while upper respiratory symptoms such 
Table 2 Imaging findings at Chest CT from three studies of 225 patients with confirmed COVID-19 pneumonia [61-63]

\begin{tabular}{|c|c|c|c|}
\hline & $\begin{array}{l}\text { Chung et al. [44] } \\
(n=21)\end{array}$ & Li et al. $[45](n=83)$ & $\begin{array}{l}\text { Bernheim } \\
\text { et al. [46] } \\
(\mathrm{n}=121)\end{array}$ \\
\hline \multicolumn{4}{|l|}{ GGO and consolidation } \\
\hline GGO & $18(85.7)$ & $81(97.6)$ & $91(75.2)$ \\
\hline Consolidation & $6(28.5)$ & $53(63.9)$ & $52(43.0)$ \\
\hline CT score & $9.9(0-19)$ & $5(4-8)$ & $3(0-18)$ \\
\hline \multicolumn{4}{|l|}{ Frequency of lobe involvement } \\
\hline Right upper lobe & $14(67)$ & $62(74.7)$ & $53(44)$ \\
\hline Right middle lobe & $12(57)$ & $61(73.5)$ & $50(41)$ \\
\hline Right lower lobe & $16(76)$ & $78(94)$ & $79(65)$ \\
\hline Left upper lobe & $14(67)$ & $71(85.5)$ & $58(48)$ \\
\hline Left lower lobe & $14(67)$ & 80(96.4) & $76(63)$ \\
\hline \multicolumn{4}{|l|}{ No. of lobes affected } \\
\hline 0 & $3(14)$ & NA & $27(22)$ \\
\hline 1 & $1(5)$ & NA & $18(15)$ \\
\hline 2 & $2(10)$ & NA & $14(12)$ \\
\hline 3 & $3(14)$ & NA & $11(9)$ \\
\hline 4 & $4(19)$ & NA & $18(15)$ \\
\hline 5 & $8(38)$ & NA & $33(27)$ \\
\hline Bilateral lung disease & $16(76)$ & NA & $73(60)$ \\
\hline \multicolumn{4}{|c|}{ Opacification distribution and pattern } \\
\hline Rounded morphology & $7(33)$ & NA & $65(54)$ \\
\hline Linear opacities & $3(14)$ & $54(65.1)$ & $9(7)$ \\
\hline Interlobular septal thickening & NA & $52(62.7)$ & NA \\
\hline Bronchial wall thickening & NA & 19(22.9) & $14(12)$ \\
\hline Crazy-paving pattern & $4(19)$ & $30(36.1)$ & $6(5)$ \\
\hline Peripheral distribution & $7(33)$ & NA & $63(52)$ \\
\hline Cavitation & $0(0)$ & NA & $0(0)$ \\
\hline \multicolumn{4}{|l|}{ Other findings } \\
\hline Discrete pulmonary nodules & $0(0)$ & $6(7.2)$ & $0(0)$ \\
\hline Pleural effusion & $0(0)$ & $7(8.4)$ & $1(1)$ \\
\hline Lymphadenopathy & $0(0)$ & $7(8.4)$ & $0(0)$ \\
\hline Pulmonary emphysema & $0(0)$ & NA & $2(2)$ \\
\hline Pulmonary fibrosis & $0(0)$ & NA & $0(0)$ \\
\hline
\end{tabular}

Data are $\mathrm{n}(\%)$ and median (IQR)

$G G O$ ground-glass opacities, $N A$ not available as rhinorrhea were rare [6]. Furthermore, chest CT findings of COVID-19 presented multilobe involvement with typical ground-glass opacity and/or consolidation [51]. Finally, nasopharyngeal swabs with positive viral RNA remain the gold standard for the diagnosis of COVID-19 [52]. However, asymptomatic infections or normal chest CT findings followed by diagnosis can also often occur. In addition, RNA tests can also produce initially false negative results due to low viral load or the method of collecting nasopharyngeal swab specimens, so samples should be taken multiple times to confirm COVID-19 [53]. Besides, the serological testing of anti-SARS-CoV-2 immunoglobulin $\mathrm{G}$ (IgG) and/or IgM was widely used as a complement method in the diagnosis of COVID-19 [54]. $\mathrm{Yu}$ et al. [55] further discovered that different specimens had different viral loads in the different stages of infection, and the average viral load in sputum was confirmed to be significantly higher than in nasal swabs and throat swabs. Furthermore, the sputum sample viral load in the recovery stage was significantly lower than that in the early and progressive stages. As such, the eventual diagnosis of COVID-19 should be determined by a comprehensive analysis of CT imaging and blood test results. 


\section{Treatment}

COVID-19 is a completely new disease that nobody knows how to treat it at first. Patients are generally on bed rest, maintained with a constant internal environment, receive supportive treatment and enough energy, and their vital signs are closely monitored. Up to now, over 1000 clinical studies have been conducted to treat COVID-19 infections in the world, including antiviral drugs, anti-inflammatories, corticosteroids, immunosuppressive agents and traditional Chinese medicine, and so on.

\section{Antiviral Drugs}

Although no antiviral treatment for COVID-19 has been proven effective, the antiretroviral drug lopinavir-ritonavir has been proposed [13], as it was previously effective in treating SARS and MERS [56, 57]. As these two viruses belong to the same branch as SARS-CoV-2, lopinavir-ritonavir may be effective against COVID-19. Cao et al. [58] found that no benefit was observed with lopinavir-ritonavir treatment beyond standard care in hospitalized patients with severe COVID-19. From the UK RECOVERY trial, 1616 patients were randomly allocated to receive lopinavir-ritonavir and 3424 patients to receive usual care, the results indicated that lopinavir-ritonavir was not supported in the treatment of hospitalized COVID-19 patients [59]. In another retrospective cohort study, arbidol combined with lopinavir-ritonavir had a better curative effect than only lopinavir-ritonavir in the treatment of COVID19-induced pneumonia, this suggested that arbidol may be superior to lopinavir-ritonavir for COVID-19 patients [60]. However, in a retrospective study, Lian et al. [61] found that arbidol may not accelerate SARS-COV-2 clearance and improve prognosis in non-ICU patients, the efficacy of arbidol needs further evaluation. Furthermore, the anti-HIV drug nelfinavir is a potent inhibitor of cell fusion caused by the SARS-CoV-2, which need further study as an antiviral against COVID-19 infections [62]. Ianevski et al. [63] found that combinations of nelfinavir with amodiaquine was effective against seven SARS-CoV-2 strains. Moreover, favipiravir is a nucleoside drug used to block virus replication to suppress the effect of the virus, in a nonrandomized trial, a significant reduction in the median time to viral clearance using favipiravir was observed. However, patients were also treated with interferon- $\alpha 1 b$, which makes it hard to estimate the antiviral effect of favipiravir, further trials need to be carried out to assess the efficacy of favipiravir against COVID-19 [64].

Meanwhile, Wang et al. [65] found that remdesivir, a novel nucleotide analog drug, could inhibit SARSCoV2 infection in vitro. Subsequently, the first case of SARSCOV-2 infection was given intravenously with remdesivir in the United States, most of the symptoms quickly subsided [31]. Sanville et al. [66] also used remdesivir to treat COVID-19 patients, which resulted in positive outcomes. In a recent study, a cohort of patients hospitalized for severe COVID-19 who were treated with compassionate-use remdesivir, clinical improvement was observed in 36 of 53 patients (68\%) [67]. These findings are only retrospective descriptive studies, which are insufficient to support the clinical application of remdesivir. Other well-designed randomized trials of remdesivir treatment have also produced results. Beige et al. [68] suggested that patients treated with remdesivir had less time to recover than those treated with placebo. In another randomized clinical trial, at day 11, moderate COVID-19 patients in the 5-day Remdesivir group had a better clinical improvement than those receiving standard treatment [69].

\section{Anti-inflammatories}

Cortegiani et al. [70] summarized six studies and 23 ongoing clinical trials in China, and demonstrated that chloroquine was effective in restricting the replication of SARS-CoV-2 in vitro, but the clinical data were insufficient. In an observational study involving 1376 patients, the results showed that hydroxychloroquine was not associated with a significant reduction or increase in the risk of intubation composite endpoints or death [71]. Besides, preliminary findings suggested that the higher chloroquine dosage should not be recommended for critically ill patients with COVID-19 because of its potential safety hazards on a Randomized Clinical Trial [72]. Moreover, on one retrospective multicenter cohort study, patients hospitalized with COVID-19, treatment with hydroxychloroquine, azithromycin, compared with either treatment, or both, was not significantly associated with differences in in-hospital mortality [73]. Besides, on June 15, 2020, the US Food and Drug Administration (FDA) revoked the emergency authorization for chloroquine and hydroxychloroquine for the treatment of some COVID-19 patients due to poor efficacy and side effects. Drugs can cause serious adverse cardiac reactions and other potential side effects, and the known and potential risks of drug use outweigh the benefits. Besides, relevant studies have found that chloroquine and hydroxychloroquine have no significant antiviral effect on SARS-COV-2 infection in rhesus monkeys or human lung cells, and these studies do not support the use of hydroxychloroquine and chloroquine in the treatment of COVID-19 infected infections [74, 75]. Aditionally, Baron et al. [76] suggested that teicoplanin may potentially treat COVID-19 patients, as it had exhibited efficacy in inhibiting the initial stage of the MERS-CoV viral cycle in human cells. In a cohort of 21 patients, infections were complementarily 
treated with teicoplanin, none of the patients had adverse effects related to teicoplanin administration. The role of teicoplanin in the treatment of SARS-CoV-2 is required to further clinical investigation [77].

\section{Corticosteroids}

Meanwhile, corticosteroids have received worldwide attention as a potentially effective treatment for COVID-19, Angus et al. [78] showed that among patients with severe COVID-19, treatment with a 7-day fixed-dose course of hydrocortisone or shock-dependent dosing of hydrocortisone, compared with no hydrocortisone, resulted in $93 \%$ and $80 \%$ probabilities of superiority with regard to the odds of improvement in organ support-free days within 21 days. Tomazini et al. [79] also found that among patients with COVID-19 and moderate or severe ARDS, use of intravenous dexamethasone plus standard care compared with standard care alone resulted in a statistically significant increase in the number of ventilator-free days over 28 days, so corticosteroids are now a standard of therapy in severely ill patients with COVID-19 based on the RECOVERY trial.

\section{Immunosuppressive Agents}

Moreover, some clinical trials on the efficacy of immunosuppressive agents in the treatment of COVID-19 are being investigated. In one randomized clinical trial, researchers showed that participants who received colchicine had statistically significantly improved time to clinical deterioration [80]. Cao et al. [81] found significant chest computed tomography improvement, a faster recovery from lymphopenia, and favorable side-effect profile in the ruxolitinib group were encouraging and informative to future trials to test efficacy of ruxolitinib in a larger population. Stone et al. [82] found that tocilizumab was not effective for preventing intubation or death in moderately ill hospitalized patients with Covid19 in a randomized, double-blind, placebo-controlled trial.

\section{Traditional Chinese Medicine}

Furthermore, traditional Chinese medicine (TCM) has played an extremely important role in the fight against COVID-19. In the third version COVID-19 treatment guidelines, the Chinese authorities announced that TCM was one of the recommended therapeutic options for COVID-19. In China, more than $30 \mathrm{TCM}$ formulae were used in Hubei to fight the COVID-19. For example, in a multicenter, prospective, randomized controlled trial in confirmed cases with COVID-19, the recovery rate was significantly higher in treatment group with Lianhuaqingwen capsules (4 capsules, thrice daily) compared with control group (91.5\% vs. $82.4 \%$ ), the rate of improvement in chest computed tomographic images (83.8\% vs. $64.1 \%$ ) and clinical cure (78.9\% vs. $66.2 \%$ ) in treatment group was also higher than control group [83]. In total, TCM has been used in $91.5 \%$ of confirmed COVID-19 cases in China. Clinical observation showed that the total effective rate of TCM reached over $90 \%$. TCM can effectively alleviate symptoms, reduce the development of mild and normal to severe, improve the cure rate, reduce the death rate, and promote the recovery of the body during the convalescent period (http://www.gov.cn/ xinwen/2020-03/23/content_5494694.htm).

To sum up, corticosteroids, remdesivir and traditional Chinese medicine have shown to be clinically effective against COVID-19 in clinical trials so far. Lopinavir-ritonavir, chloroquine and hydroxychloroquine were initially promising are no longer being used because of lack of efficacy from clinical trials. Tocilizumab was not effective for preventing death in moderately ill hospitalized COVID19 patients. The efficacy of arbidol, favipiravir, teicoplanin, ruxolitinib and colchicine are still undergoing further evaluation.

\section{Vaccine}

Vaccination is the most effective method for a long-term strategy for prevention and control of COVID-19 in the future. As of January 18, 2021, more than 214 vaccine candidates for COVID-19 had been reported and over 50 vaccine candidates were under clinical evaluation to treat COVID-19 around the world. At present, 15 vaccines from 5 technical routes are in clinical trials in China, and 6 of them are undergoing phase III clinical trials according to procedures and standards. Chen et al. [84, 85] has developed the world's first recombinant coronavirus vaccine (AD5-NCOV) and completed phase I and II clinical trials, 4 weeks after vaccination, $99.5 \%$ of the subjects to produce specific antibodies, $89 \%$ of the subjects had a specific cellular immune response, the phase I and II clinical trials in general has reached the expected results. Chen's team started phase III clinical trials of the COVID-19 vaccine in September this year in Mexico and expect to see preliminary phase III clinical results in three to six months. Besides, the Pfizer vaccine entered phase III trials on July $27,43,538$ people participated in the phase III trial, the results of the phase III clinical trial showed that a two-dose regimen of Pfizer vaccine (BNT162b2) conferred 95\% protection against COVID-19 among people over the age of 16 [86]. On 2 December, the UK government announced that it had approved the Pfizer COVID-19 vaccine for its citizens, making the UK the first country in the world to do so, subsequently, the Pfizer vaccine was approved in Canada, the United States, Singapore and other countries. Besides, the Moderna vaccine entered phase III clinical trials on 27 July, and has enrolled roughly 
30,000 people, making it the world's first phase III clinical COVID-19 mRNA vaccine. On November 6, a preliminary Moderna data show that the immunization is $94 \%$ effective and seems to prevent severe infections, on the basis of an analysis of 95 cases in its ongoing phase III efficacy trial. Of these, 90 were in the group that received a placebo injection and 5 had received the vaccine, which equates to an efficacy of $94.5 \%$ [87]. On December 18, the US Food and Drug Administration (FDA) approved an emergency license for Moderna COVID-19 vaccine, the second COVID-19 vaccine to be approved in the US, following Pfizer vaccine. In addition, in an interim analysis of four randomised controlled trials in South Africa, Brazil, and the UK, they found that the efficacy of the Oxford vaccine (AZD1222) was $62.1 \%$ (in participants who received two standard doses) and $90.0 \%$ (in participants who received a low dose followed by a standard dose). Overall vaccine efficacy across both groups was $70.4 \%$ [88]. On December 30, the Oxford vaccine was officially approved for clinical use by the Medicines and Healthcare Products Regulatory Agency (MHRA). This is the second COVID-19 vaccine approved for use in the UK, after the Pfizer vaccine. Furthermore, On December 30, developed by Beijing biotechnology company COVID-19 vaccine phase III clinical trial data showed that the vaccine effectiveness was $79.34 \%$, the data meet the world health organization-related technical standard, the vaccine has been approved by the State Food and Drug Administration for conditional marketing (http://www.bjbpi.com/news_list.asp? $\mathrm{id}=787$ ). We expect more effective vaccines to be put on the market to fight the pandemic.

\section{Intervention and Prevention Experience from China}

At present, China's epidemic prevention and control efforts have achieved steady success. To sum up, the stage of fighting the epidemic can be divided into the following four stages. In the first stage, at the end of December 2019, a case of pneumonia of unknown cause was discovered in Wuhan. The Chinese government immediately reported the outbreak and took prompt action to carry out etiological and epidemiological investigations.

In the second stage, that was, the outbreak period, began in late January, 2020. SARS-CoV-2 infection has been legally classified as a category B infectious disease but has been managed as a category A infectious disease by the Chinese authorities. With the number of confirmed cases rising rapidly across the country, China has adopted a key strategy to stop the spread of the virus. Wuhan as a largest city in central China ( $>11$ million inhabitants), the epicenter of the COVID19 outbreak, and was locked down in an effort to curb rapid transmission on 23 January 2020, the lockdown of Wuhan's public transportation, including trains, buses, subway, and airport, was also enforced to prevent the spread of the outbreak. Subsequently, other cities in Hubei province took similar measures, 30 other provinces also launched public health emergency response measures, many other cities also implemented the unprecedented intervention, and these effective experiences could improve public health response against the pandemic on global levels $[89,90]$. At the same time, citizens leaving Wuhan must report to the local government and were required to be quarantined in designated places for 14 days. Due to the increasing number of infected cases in Wuhan, the medical resources in Hubei province were seriously insufficient; at the critical moment, the Chinese government has arranged more than 40,000 medical workers to support Hubei province [91]. At the same time, the Chinese government quickly constructed two designated hospitals (Huoshenshan and Leishenshan hospital) which could provide a total of over 2,000 beds for severe patients and more than a dozen Fangcang shelter hospitals for mild patients. Fangcang shelter hospitals quarantined thousands of confirmed cases, provided considerate medical services, and achieved an important triage function; it proved that the Fangcang shelter hospitals were the main reason for the success of epidemic prevention, other countries confronting the COVID-19 infection should also consider using Fangcang shelter hospitals as part of their public health response [92, 93].

For each individual, to further cut off potential transmission routes, Chinese authorities applied communitywide containment measures to reduce personal interactions; residents were asked to stay at home, and crowded areas such as schools and shopping malls were closed. Furthermore, all close contacts of confirmed patients and suspected patients were required for forced isolation in special places and received medical observation for 14 days. Due to the possibility of RNA tests turning positive again, the discharged patients were transferred to designated places to receive medical observation for another 14 days before returning home.

In the third stage, since late March, the number of newly confirmed cases in Wuhan has been reduced to zero, and the epidemic in China has achieved initial success. Subsequently, the control measures for leaving Wuhan were lifted, and the number of COVID-19 patients in hospitals in Wuhan was cleared, which marked that the spread of COVID-19 in Wuhan, the main battlefield in China, was basically interrupted. In order to find out Wuhan current situation of COVID-19, the Wuhan government decided to start novel Coronavirus nucleic acid screening for 10 million citizens within two weeks, screening results found no new symptomatic cases and 300 asymptomatic cases, and no positive cases were detected among 1,174 close contacts of asymptomatic cases, therefore, five to eight weeks after 
the lockdown ended, the infection rate of SARS-COV-2 in Wuhan was very low [94].

In the fourth stage, since 29 April 2020, the epidemic situation in China has been sporadic on the whole, imported cases from abroad have been basically brought under control, and the epidemic prevention and control across the country has entered a normal state. For example, confirmed cases have been found in Beijing, Qingdao, Shanghai, Xinjiang and Inner Mongolia one after the other; once there were confirmed cases in a locality, the local government will conduct nucleic acid tests for all personnel in the area, it took Qingdao five days to conduct nucleic acid tests on 7.5 million people in the city, full and thorough screening of possible infections.

On the whole, China's response to the epidemic has been successful, this is due to strict epidemic prevention measures and people's trust in the government. It proved that the early adoption of strict measures was of great significance for the control of COVID-19 outbreak, which could avoid local outbreaks caused by imported cases. But even when a local epidemic occurs, adopting high-intensity intervention and prevention measures in time, early detection and treatment of cases, suspected cases and close contacts to take strict medical quarantine and management, monitoring and screening of people who have moved in from the worst-affected areas, minimize public gathering activities, and also can effectively control the spread of the epidemic.

\section{Conclusions}

SARS-CoV-2 has become a pandemic, the number of infected people is still increasing rapidly, especially in some European and American countries. After three months of efforts, the epidemic in China has been effectively controlled, confirming that containment is viable. Other countries should take action immediately to reduce the spread of COVID-19. To date, the SARS-CoV-2 outbreak has lasted for a year, many issues remain unclear regarding COVID-19. First, the outbreak was first declared in Wuhan; however, this does not mean the source was there, and further investigation is needed. Second, it is unclear whether discharged patients can regain COVID-19 positivity and thus infectivity. Third, asymptomatic infections can transmit the disease, but the length and strength of the infectious period are to be determined, which is the focus and difficulty of formulation of containment measures at the present stage. The mechanism by which the virus causes asymptomatic infections and can still be transmitted is still unclear and requires further research. Finally, specific antiviral drugs are still not available and exist a lot of uncertainty about COVID-19 pneumonia. Although the domestic outbreak has been effectively controlled, the imported cases from abroad pose a new challenge to China. Thus, each of us still needs to be vigilant and not let down to prevent a second outbreak.

Acknowledgments We thank Editideas (www.editideas.cn) for its linguistic assistance during the preparation of this manuscript.

Authors' Contributions All authors contributed to this manuscript and approved the final manuscript. CW performed the selection of literature, drafted the manuscript, and prepared table. XX, HF, ZH, NT, $\mathrm{XL}, \mathrm{KW}$ and ML collected the related references and participation in discussion. LB designed this review and revised the manuscript. All authors contributed to this manuscript. All authors read and approved the final manuscript.

Funding This work was supported in part, by the National Natural Science Foundation of China (81871419), Young medical reserve talents projects in Hubei Province and Seed fund support plan of Sino foreign joint research platform in Wuhan University (2309-413100006).

\section{Compliance with Ethical Standards}

Conflict of interest All authors declared no conflict of interest.

Consent for Publication All authors have agreed on the consent of the manuscript.

\section{References}

1. Zhu N, Zhang D, Wang W, Li X, Yang B et al (2020) A novel coronavirus from patients with pneumonia in China, 2019. N Engl J Med 382(8):727-733. https://doi.org/10.1056/NEJMoa2001017

2. Lu RJ, Zhao X, Li J, Niu PH, Yang B et al (2020) Genomic characterisation and epidemiology of 2019 novel coronavirus: implications for virus origins and receptor binding. Lancet 395(10224):565-574. https://doi.org/10.1016/s0140-6736(20) 30251-8

3. Adachi S, Koma T, Doi N, Nomaguchi M, Adachi A (2020) Commentary: origin and evolution of pathogenic coronaviruses. Front Immunol. https://doi.org/10.3389/fimmu.2020.00811

4. Chan JF-W, Yuan S, Kok K-H, To KK-W, Chu H et al (2020) A familial cluster of pneumonia associated with the 2019 novel coronavirus indicating person-to-person transmission: a study of a family cluster. Lancet 395(10223):514-523. https://doi.org/10. 1016/s0140-6736(20)30154-9

5. Li Q, Guan X, Wu P, Wang X, Zhou L et al (2020) Early transmission dynamics in Wuhan, China, of novel coronavirus-infected pneumonia. N Eng1 J Med 382(13):1199-1207. https://doi.org/ 10.1056/NEJMoa2001316

6. Guan WJ, Ni ZY, Hu Y, Liang WH, Ou CQ et al (2020) Clinical characteristics of coronavirus disease 2019 in China. N Engl J Med 382(18):1708-1720. https://doi.org/10.1056/NEJMoa2002 032

7. Wang D, Hu B, Hu C, Zhu F, Liu X, Zhang J, Wang B et al (2020) Clinical characteristics of 138 hospitalized patients with 2019 novel coronavirus-infected pneumonia in Wuhan. China Jama 323(11):1061-1069. https://doi.org/10.1001/jama.2020.1585

8. Rothe C, Schunk M, Sothmann P, Bretzel G, Froeschl G et al (2020) Transmission of 2019-nCoV infection from an asymptomatic contact in Germany. N Engl J Med 382(10):970-971. https://doi.org/10.1056/NEJMc2001468 
9. Chang LM, Wei L, Xie L, Zhu G, Dela Cruz CS, Sharma L (2020) Epidemiologic and clinical characteristics of novel coronavirus infections involving 13 patients outside Wuhan, China. Jama 323(11):1092-1093. https://doi.org/10.1001/jama.2020.1623

10. Young BE, Ong SWX, Kalimuddin S, Low JG, Tan SY et al (2020) Epidemiologic features and clinical course of patients infected with SARS-CoV-2 in Singapore. JAMA 323(15):14881494. https://doi.org/10.1001/jama.2020.3204

11. Tian S, Hu N, Lou J, Chen K, Kang X et al (2020) Characteristics of COVID-19 infection in Beijing. J Infect 80(4):401-406. https:// doi.org/10.1016/j.jinf.2020.02.018

12. Chen J, Qi T, Liu L, Ling Y, Qian Z, Li T et al (2020) Clinical progression of patients with COVID-19 in Shanghai, China. J Infect 80(5):e1-e6. https://doi.org/10.1016/j.jinf.2020.03.004

13. Huang C, Wang Y, Li X, Ren L, Zhao J, Hu Y et al (2020) Clinical features of patients infected with 2019 novel coronavirus in Wuhan. China Lancet 395(10223):497-506. https://doi.org/10. 1016/s0140-6736(20)30183-5

14. Weiss SR, Leibowitz JL (2011) Coronavirus pathogenesis. Adv Virus Res. https://doi.org/10.1016/b978-0-12-385885-6.00009-2

15. Yang D, Leibowitz JL (2015) The structure and functions of coronavirus genomic 3' and 5' ends. Virus Res 206:120-133. https:// doi.org/10.1016/j.virusres.2015.02.025

16. Xu X, Chen P, Wang J, Feng J, Zhou H, Li X, Zhong W, Hao $P$ (2020) Evolution of the novel coronavirus from the ongoing Wuhan outbreak and modeling of its spike protein for risk of human transmission. Sci China Life Sci 63(3):457-460. https:// doi.org/10.1007/s11427-020-1637-5

17. Zhou P, Yang XL, Wang XG, Hu B, Zhang L et al (2020) A pneumonia outbreak associated with a new coronavirus of probable bat origin. Nature 579(7798):270-273. https://doi.org/10.1038/ s41586-020-2012-7

18. Ceraolo C, Giorgi FM (2020) Genomic variance of the 2019nCoV coronavirus. J Med Virol 92(5):522-528. https://doi.org/ 10.1002/jmv. 25700

19. Xiao K, Zhai J, Feng Y, Zhou N, Zhang X et al (2020) Isolation of SARS-CoV-2-related coronavirus from Malayan pangolins. Nature 583(7815):286-289. https://doi.org/10.1038/ s41586-020-2313-x

20. Lam TT, Shum MH, Zhu HC, Tong YG, Ni XB et al (2020) Identifying SARS-CoV-2 related coronaviruses in Malayan pangolins. Nature 583(7815):282-285. https://doi.org/10.1038/ s41586-020-2169-0

21. Shi J, Wen Z, Zhong G, Yang H, Wang C et al (2020) Susceptibility of ferrets, cats, dogs, and other domesticated animals to SARS-coronavirus 2. Science 368(6494):1016-1020. https://doi. org/10.1126/science.abb7015

22. Richard M, Kok A (2020) SARS-CoV-2 is transmitted via contact and via the air between ferrets. Nat Commun 11(1):3496. https:// doi.org/10.1038/s41467-020-17367-2

23. Backer JA, Klinkenberg D, Wallinga J (2020) Incubation period of 2019 novel coronavirus (2019-nCoV) infections among travellers from Wuhan, China, 20-28 January 2020. Euro Surveillance. https://doi.org/10.2807/1560-7917.es.2020.25.5.2000062

24. Ki M, nCo VT (2020) Epidemiologic characteristics of early cases with 2019 novel coronavirus (2019-nCoV) disease in Republic of Korea. Epidemiol Health. https://doi.org/10.4178/epih.e2020007

25. Yang Y, Lu Q, Liu M, Wang Y, Zhang A, Jalali N et al (2020) Epidemiological and clinical features of the 2019 novel coronavirus outbreak in China. medRxiv:2020.2002.2010.20021675. https:// doi.org/10.1101/2020.02.10.20021675

26. Li J, Wang Y, Gilmour S, Wang M, Yoneoka D et al (2020) Estimation of the epidemic properties of the 2019 novel coronavirus: a mathematical modeling study. medR xiv:2020.2002.2018.20024315. https://doi.org/10.1101/2020.02. 18.20024315
27. Peeri NC, Shrestha N, Rahman MS, Zaki R et al (2020) The SARS, MERS and novel coronavirus (COVID-19) epidemics, the newest and biggest global health threats: what lessons have we learned? Int J Epidemiol 49(3):717-726. https://doi.org/10. 1093/ije/dyaa033

28. Wu Z, McGoogan JM (2020) Characteristics of and important lessons from the Coronavirus Disease 2019 (COVID-19) outbreak in China: Summary of a Report of 72314 cases From the Chinese center for disease control and prevention. JAMA 323(13):1239-1242. https://doi.org/10.1001/jama.2020.2648

29. Lu CW, Liu XF, Jia ZF (2020) 2019-nCoV transmission through the ocular surface must not be ignored. Lancet 395(10224):e39. https://doi.org/10.1016/s0140-6736(20)30313-5

30. Kim Y-I, Kim S-G, Kim S-M, Kim E-H et al (2020) Infection and rapid transmission of SARS-CoV-2 in ferrets. Cell Host Microbe 27(5):704-709. https://doi.org/10.1016/j.chom.2020. 03.023

31. Holshue ML, DeBolt C, Lindquist S, Lofy KH, Wiesman J, Bruce H, Spitters C, Ericson K, Wilkerson S, Tural A, Diaz G, Cohn A, Fox L, Patel A et al (2020) First case of 2019 novel coronavirus in the United States. N Engl J Med 382(10):929-936. https://doi. org/10.1056/NEJMoa2001191

32. Luo S, Zhang X, Xu H (2020) Don't overlook digestive symptoms in patients with 2019 novel coronavirus disease (COVID-19). Clin Gastroenterol Hepatol 18(7):1636-1637. https://doi.org/10.1016/j. cgh.2020.03.043

33. Qiao J (2020) What are the risks of COVID-19 infection in pregnant women? Lancet 395(10226):760-762. https://doi.org/10. 1016/s0140-6736(20)30365-2

34. Deng W, Bao L, Gao H, Xiang Z, Qu Y et al (2020) Rhesus macaques can be effectively infected with SARS-CoV-2 via ocular conjunctival route. bioRxiv:2020.2003.2013.990036. https:// doi.org/10.1101/2020.03.13.990036

35. Wang Y, Liu Y, Liu L, Wang X, Luo N, Ling L (2020) Clinical outcome of 55 asymptomatic cases at the time of hospital admission infected with SARS-Coronavirus-2 in Shenzhen, China. J Infect Dis. 1:150. https://doi.org/10.1093/infdis/jiaa119

36. Dell'Era V, Farri F, Garzaro G, Gatto M, Aluffi Valletti P, Garzaro M (2020) Smell and taste disorders during COVID-19 outbreak: cross-sectional study on 355 patients. Head Neck 42(7):15911596. https://doi.org/10.1002/hed.26288

37. Liu H, Liu F, Li J, Zhang T, Wang D, Lan W (2020) Clinical and CT imaging features of the COVID-19 pneumonia: focus on pregnant women and children. J Infect 80(5):e7-e13. https://doi. org/10.1016/j.jinf.2020.03.007

38. Qiu H, Wu J, Hong L, Luo Y, Song Q, Chen D (2020) Clinical and epidemiological features of 36 children with coronavirus disease 2019 (COVID-19) in Zhejiang, China: an observational cohort study. Lancet Infect Dis 20(6):689-696. https://doi.org/10.1016/ s1473-3099(20)30198-5

39. Zhang JJ, Dong X, Cao YY, Yuan YD, Yang YB, Yan YQ, Akdis CA, Gao YD (2020) Clinical characteristics of 140 patients infected with SARS-CoV-2 in Wuhan. China Allergy 75(7):1730 1741. https://doi.org/10.1111/all.14238

40. Liu J, Li S, Liu J, Liang B, Wang X, Wang H et al (2020) Longitudinal characteristics of lymphocyte responses and cytokine profiles in the peripheral blood of SARS-CoV-2 infected patients. EBioMedicine. https://doi.org/10.1016/j.ebiom.2020.102763

41. Yuan J, Zou R, Zeng L, Kou S, Lan J, Li X, Liang Y et al (2020) The correlation between viral clearance and biochemical outcomes of 94 COVID-19 infected discharged patients. Inflamm Res 69(6):599-606. https://doi.org/10.1007/s00011-020-01342-0

42. Pan F, Ye T (2020) Time course of lung changes on chest CT during recovery from 2019 novel coronavirus (COVID-19) pneumonia. Radiology 295(3):715-721. https://doi.org/10.1148/radiol. 2020200370 
43. Fang Y, Zhang H (2020) Sensitivity of chest CT for COVID-19: comparison to RT-PCR. Radiology 296(2):E115-E117. https:// doi.org/10.1148/radiol.2020200432

44. Chung M, Bernheim A (2020) CT imaging features of 2019 novel coronavirus (2019-nCoV). Radiology 295(1):202-207. https://doi.org/10.1148/radiol.2020200230

45. Li K, Wu J, Wu F, Guo D, Chen L, Fang Z, Li C (2020) The Clinical and chest CT features associated with severe and critical COVID-19 Pneumonia. Invest Radiol 55(6):327-331. https://doi.org/10.1097/rli.0000000000000672

46. Bernheim A, Mei X (2020) Chest CT findings in coronavirus disease-19 (COVID-19): relationship to duration of infection. Radiology 295(3):200463. https://doi.org/10.1148/radiol.20202 00463

47. Song F, Shi N, Shan F, Zhang Z, Shen J, Lu H, Ling Y (2020) Emerging 2019 novel coronavirus (2019-nCoV) pneumonia. Radiology 295(1):210-217. https://doi.org/10.1148/radiol. 2020200274

48. Caruso D, Zerunian M (2020) Chest CT features of COVID-19 in Rome, Italy. Radiology 296(2):E79-E85. https://doi.org/10.1148/ radiol.2020201237

49. Ai T, Yang Z (2020) Correlation of chest CT and RT-PCR testing in coronavirus disease 2019 (COVID-19) in China: a report of 1014 cases. Radiology 296(2):E32-E40. https://doi.org/10.1148/ radiol.2020200642

50. Yang W, Yan F (2020) Patients with RT-PCR confirmed COVID19 and normal chest CT. Radiology 295(2):E3. https://doi.org/10. 1148/radiol.2020200702

51. Shi H, Han X, Jiang N, Cao Y, Alwalid O, Gu J, Fan Y, Zheng C (2020) Radiological findings from 81 patients with COVID-19 pneumonia in Wuhan, China: a descriptive study. Lancet Infect Dis 20(4):425-434. https://doi.org/10.1016/s1473-3099(20) 30086-4

52. Yu F, Du L, Ojcius DM, Pan C, Jiang S (2020) Measures for diagnosing and treating infections by a novel coronavirus responsible for a pneumonia outbreak originating in Wuhan. China Microb Infect 22(2):74-79. https://doi.org/10.1016/j.micinf.2020.01.003

53. Zu ZY, Jiang MD, Xu PP, Chen W, Ni QQ (2020) Coronavirus disease 2019 (COVID-19): a perspective from China. Radiology 296(2):E15-E25. https://doi.org/10.1148/radiol.2020200490

54. Zhang Z-L, Hou Y-L, Li D-T, Li F-Z (2020) Diagnostic efficacy of anti-SARS-CoV-2 IgG/IgM test for COVID-19: a meta-analysis. J Med Virol. https://doi.org/10.1002/jmv.26211

55. Yu F, Yan L, Wang N, Yang S, Wang L, Tang Y et al (2020) Quantitative detection and viral load analysis of SARS-CoV-2 in infected patients. Clin Infect Dis 71(15):793-798. https://doi.org/ $10.1093 / \mathrm{cid} / \mathrm{ciaa} 345$

56. Chu CM, Cheng VC, Hung IF, Wong MM, Chan KH et al (2004) Role of lopinavir/ritonavir in the treatment of SARS: initial virological and clinical findings. Thorax 59(3):252-256. https://doi. org/10.1136/thorax.2003.012658

57. Momattin H, Al-Ali AY, Al-Tawfiq JA (2019) A systematic review of therapeutic agents for the treatment of the Middle East Respiratory Syndrome Coronavirus (MERS-CoV). Travel Med Infect Dis 30:9-18. https://doi.org/10.1016/j.tmaid.2019.06.012

58. Cao B, Wang Y, Wen D, Liu W, Wang J, Fan G et al (2020) A trial of Lopinavir-Ritonavir in adults hospitalized with severe Covid19. N Engl J Med 382(19):1787-1799. https://doi.org/10.1056/ NEJMoa2001282

59. Lopinavir-ritonavir in patients admitted to hospital with COVID19 (RECOVERY): a randomised, controlled, open-label, platform trial (2020). Lancet 396(10259):1345-1352. https://doi.org/10. 1016/s0140-6736(20)32013-4

60. Deng L, Li C, Zeng Q, Liu X, Li X, Zhang H, Hong Z, Xia J (2020) Arbidol combined with LPV/r versus LPV/r alone against
Corona Virus Disease 2019: a retrospective cohort study. J Infect 81(1):e1-e5. https://doi.org/10.1016/j.jinf.2020.03.002

61. Lian N, Xie H, Lin S, Huang J, Zhao J, Lin Q (2020) Umifenovir treatment is not associated with improved outcomes in patients with coronavirus disease 2019: a retrospective study. Clin Microbiol Infect 26(7):917-921. https://doi.org/10.1016/j.cmi. 2020.04.026

62. Musarrat F, Chouljenko V, Dahal A, Nabi R, Chouljenko T, Jois SD, Kousoulas KG (2020) The anti-HIV drug nelfinavir mesylate (Viracept) is a potent inhibitor of cell fusion caused by the SARSCoV-2 spike (S) glycoprotein warranting further evaluation as an antiviral against COVID-19 infections. J Med Virol 92(10):2087-2095. https://doi.org/10.1002/jmv.25985

63. Ianevski A, Yao R, Fenstad MH, Biza S, Zusinaite E et al (2020) Potential antiviral options against SARS-CoV-2 infection. Viruses 12(6):642. https://doi.org/10.3390/v12060642

64. Cai Q, Yang M, Liu D, Chen J, Shu D, Xia J et al (2020) Experimental treatment with Favipiravir for COVID-19: an open-label control study. Engineering (Beijing) 6(10):1192-1198. https:// doi.org/10.1016/j.eng.2020.03.007

65. Wang M, Cao R, Zhang L, Yang X, Liu J, Xu M, Shi Z, Hu $Z$ (2020) Remdesivir and chloroquine effectively inhibit the recently emerged novel coronavirus $(2019-\mathrm{nCoV})$ in vitro. Cell Res 30(3):269-271. https://doi.org/10.1038/s41422-020-0282-0

66. Sanville B, Corbett R, Pidcock W, Hardin K, Sebat C, Nguyen M-V, Thompson GR, Haczku A, Schivo M, Cohen S (2020) A Community transmitted case of severe acute respiratory distress syndrome due to SARS CoV2 in the United States. Clin Infect Dis 71(16):2222-2226. https://doi.org/10.1093/cid/ciaa347

67. Grein J, Ohmagari N, Shin D, Diaz G, Asperges E, Castagna A et al (2020) Compassionate use of Remdesivir for patients with severe Covid-19. N Engl J Med 382(24):2327-2336. https://doi. org/10.1056/NEJMoa2007016

68. Beigel JH, Tomashek KM, Dodd LE, Mehta AK, Zingman BS et al (2020) Effect of Remdesivir vs standard care on clinical status at 11 days in patients with moderate COVID-19: a Randomized Clinical Trial. JAMA 324(11):1048-1057. https://doi. org/10.1001/jama.2020.16349

69. Spinner CD, Gottlieb RL, Criner GJ, Arribas López JR, Cattelan AM et al (2020) Effect of Remdesivir vs standard care on clinical status at 11 days in patients with moderate COVID-19: a Randomized Clinical Trial. JAMA 324(11):1048-1057. https:// doi.org/10.1001/jama.2020.16349

70. Cortegiani A, Ingoglia G, Ippolito M, Giarratano A, Einav S (2020) A systematic review on the efficacy and safety of chloroquine for the treatment of COVID-19. J Crit Care 57:279-283. https://doi.org/10.1016/j.jcrc.2020.03.005

71. Geleris J, Sun Y, Platt J, Zucker J, Baldwin M et al (2020) Observational study of hydroxychloroquine in hospitalized patients with Covid-19. N Eng1 J Med 382(25):2411-2418. https://doi.org/10.1056/NEJMoa2012410

72. Borba MGS, Val FFA, Sampaio VS, Alexandre MAA et al (2020) Effect of high vs low doses of chloroquine diphosphate as adjunctive therapy for patients hospitalized with Severe Acute Respiratory Syndrome Coronavirus 2 (SARS-CoV-2) infection: a Randomized Clinical Trial. JAMA Netw Open 3(4):e208857. https://doi.org/10.1001/jamanetworkopen.2020. 8857

73. Rosenberg ES, Dufort EM, Udo T, Wilberschied LA et al (2020) Association of treatment with hydroxychloroquine or Azithromycin with in-hospital mortality in patients with COVID-19 in New York State. JAMA 323(24):2493-2502. https://doi.org/10. 1001/jama.2020.8630

74. Maisonnasse P, Guedj J (2020) Hydroxychloroquine use against SARS-CoV-2 infection in non-human 
primates. Nature 585(7826):584-587. https://doi.org/10.1038/ s41586-020-2558-4

75. Hoffmann M, Mösbauer K, Hofmann-Winkler H et al (2020) Chloroquine does not inhibit infection of human lung cells with SARS-CoV-2. Nature 585(7826):588-590. https://doi.org/10. 1038/s41586-020-2575-3

76. Baron SA, Devaux C, Colson P, Raoult D, Rolain JM (2020) Teicoplanin: an alternative drug for the treatment of coronavirus COVID-19? Int J Antimicrob Agents 55(4):105944. https://doi. org/10.1016/j.ijantimicag.2020.105944

77. Ceccarelli G, Alessandri F, d'Ettorre G, Borrazzo C et al (2020) Is teicoplanin a complementary treatment option for COVID-19? The question remains. Int J Antimicrob Agents 56(2):106029. https://doi.org/10.1016/j.ijantimicag.2020.106029

78. Angus DC, Derde L, Al-Beidh F, Annane D et al (2020) Effect of hydrocortisone on mortality and organ support in patients with severe COVID-19: the REMAP-CAP COVID-19 Corticosteroid Domain Randomized Clinical Trial. JAMA 324(13):1317-1329. https://doi.org/10.1001/jama.2020.17022

79. Tomazini BM, Maia IS, Cavalcanti AB et al (2020) Effect of dexamethasone on days alive and ventilator-free in patients with moderate or severe acute respiratory distress syndrome and COVID19: the CoDEX randomized clinical trial. JAMA Netw Open 324(13):1307-1316. https://doi.org/10.1001/jama.2020.17021

80. Deftereos SG, Giannopoulos G, Vrachatis DA et al (2020) Effect of colchicine vs standard care on cardiac and inflammatory biomarkers and clinical outcomes in patients hospitalized with coronavirus disease 2019: the GRECCO-19 randomized clinical trial. JAMA Network Open 3(6):e2013136. https://doi.org/10.1001/ jamanetworkopen.2020.13136

81. Cao Y, Wei J, Zou L, Jiang T, Wang G, Chen L et al (2020) Ruxolitinib in treatment of severe coronavirus disease 2019 (COVID19): a multicenter, single-blind, randomized controlled trial. J Allergy Clin Immunol 146(1):137-146. https://doi.org/10.1016/j. jaci.2020.05.019

82. Stone JH, Frigault MJ, Serling-Boyd NJ et al (2020) Efficacy of Tocilizumab in patients hospitalized with Covid-19. N Engl J Med 383(24):2333-2344. https://doi.org/10.1056/NEJMoa2028836

83. Hu K, Guan WJ, Bi Y, Zhang W, Li L et al (2020) Efficacy and safety of Lianhuaqingwen capsules, a repurposed Chinese herb, in patients with coronavirus disease 2019: a multicenter, prospective, randomized controlled trial. Phytomedicine. https://doi.org/ 10.1016/j.phymed.2020.153242

84. Zhu F-C, Li Y-H, Guan X-H, Hou L-H, Wang W-J et al (2020) Safety, tolerability, and immunogenicity of a recombinant adenovirus type-5 vectored COVID-19 vaccine: a dose-escalation, open-label, non-randomised, first-in-human trial. Lancet
395(10240):1845-1854. https://doi.org/10.1016/S0140-6736(20) 31208-3

85. Zhu FC, Guan XH, Li YH, Huang JY, Jiang T et al (2020) Immunogenicity and safety of a recombinant adenovirus type5 -vectored COVID-19 vaccine in healthy adults aged 18 years or older: a randomised, double-blind, placebo-controlled, phase 2 trial. Lancet 396(10249):479-488. https://doi.org/10.1016/s01406736(20)31605-6

86. Polack FP, Thomas SJ, Kitchin N, Absalon J, Gurtman A et al (2020) Safety and efficacy of the BNT162b2 mRNA Covid-19 vaccine. N Engl J Med. https://doi.org/10.1056/NEJMoa2034577

87. Callaway E (2020) COVID vaccine excitement builds as Moderna reports third positive result. Nature 587(7834):337-338. https:// doi.org/10.1038/d41586-020-03248-7

88. Voysey M, Clemens SAC, Madhi SA, Weckx LY et al (2021) Safety and efficacy of the ChAdOx1 nCoV-19 vaccine (AZD1222) against SARS-CoV-2: an interim analysis of four randomised controlled trials in Brazil, South Africa, and the UK. Lancet 397(10269):99-111. https://doi.org/10.1016/s0140-6736(20) 32661-1

89. Ji T, Chen HL, Xu J, Wu LN, Li JJ, Chen K, Qin G (2020) Lockdown contained the spread of 2019 novel coronavirus disease in Huangshi city, China: early epidemiological findings. Clin Infect Dis 71(6):1454-1460. https://doi.org/10.1093/cid/ciaa390

90. Ruan L, Wen M, Zeng Q, Chen C, Huang S et al (2020) New measures for COVID-19 response: a lesson from the Wenzhou experience. Clin Infect Dis 71(15):866-869. https://doi.org/10. 1093/cid/ciaa386

91. Zhang Z, Yao W, Wang Y, Long C, Fu X (2020) Wuhan and Hubei COVID-19 mortality analysis reveals the critical role of timely supply of medical resources. J Infect 81(1):147-178. https://doi. org/10.1016/j.jinf.2020.03.018

92. Chen S, Zhang Z, Yang J, Wang J, Zhai X, Barnighausen T, Wang C (2020) Fangcang shelter hospitals: a novel concept for responding to public health emergencies. Lancet 395(10232):1305-1314. https://doi.org/10.1016/s0140-6736(20)30744-3

93. Meng L, Qiu F, Sun S (2020) Providing pharmacy services at cabin hospitals at the coronavirus epicenter in China. Int J Clin Pharm 42(2):305-308. https://doi.org/10.1007/s11096-020-01020-5

94. Cao S, Gan Y, Wang C, Bachmann M, Wei S et al (2020) Postlockdown SARS-CoV-2 nucleic acid screening in nearly ten million residents of Wuhan. China Nat Commun 11(1):5917. https:// doi.org/10.1038/s41467-020-19802-w

Publisher's Note Springer Nature remains neutral with regard to jurisdictional claims in published maps and institutional affiliations. 